\title{
Educação e Práticas Para Promoção de Saúde Mental na Adolescência
}

\author{
Damaris Wehrmann Robaert ${ }^{1}$ \\ Elisiane Felzke Schonardie ${ }^{2}$
}

\begin{abstract}
Resumo
Este texto constitui-se relato de uma pesquisa desenvolvida durante o curso de Pós-Graduação Lato Sensu em Saúde Mental. Ela consiste em uma abordagem qualitativa, do tipo estudo de caso, quando se buscou compreender as concepções dos profissionais da área da psicologia no que se refere às práticas de saúde mental já desenvolvidas pelas equipes dos centros de saúde de dois campi de um Instituto Federal de Educação, Ciência e Tecnologia. Parte-se, aqui, da concepção de saúde mental construída a partir da Reforma Psiquiátrica e, consequentemente, da necessidade de construção de uma rede comunitária de atenção à saúde, podendo a escola constituir-se uma das integrantes desta. 0 motivo de ter-se optado por este caso reside no fato de referir-se a uma recente experiência de articulação entre saúde e educação - experiência diferenciada por introduzir centros de saúde, com equipes multiprofissionais, dentro das escolas. Sendo uma proposta inovadora, portanto, se faz importante compreender como os profissionais da saúde a tem percebido e como entendem as possibilidades de contribuições da escola quanto ao desenvolvimento de ações com ênfase na saúde mental dos adolescentes. Entre os resultados encontrados, destaca-se que a concepção destes apontou afirmativamente para interessantes práticas já desenvolvidas nesse sentido.
\end{abstract}

Palavras-chave: Saúde mental. Educação. Adolescência.

1 Graduação em Psicologia pela Universidade Regional do Noroeste do Estado do Rio Grande do Sul (Unijuí). Psicóloga do Instituto Federal Farroupilha, campus Santo Augusto, atuando na Coordenação de Assistência Estudantil. Tem experiência principalmente na área de Psicologia clínica e educacional. Especialização em Saúde Mental pela Unijuí e Mestrado em Educação pela Universidade Federal de Santa Maria (UFSM). damariswehrmann@yahoo.com.br

2 Graduação em Psicologia pela Universidade Regional do Noroeste do Estado do Rio Grande do Sul (Unijuí). Mestrado em Educação nas Ciências - área Psicologia. Tem experiência na área de Psicologia, com ênfase em Psicologia Clínica, Social e Educacional. Trabalha com os temas: o mal-estar na educação; aprendizagem e dificuldades de aprendizagem; a atuação do psicólogo nas instituições educativas; infância; adolescência; atenção psicossocial ao idoso; acompanhamento terapêutico; ética e psicanálise. Experiência de Coordenação do curso de Psicologia da Unijuí (campi Santa Rosa e Ijuí); Coordenação do NDE do curso de Psicologia; Coordenação Geral dos Estágios Curriculares do Curso de Psicologia. elisiane.s@unijui.edu.br 
EDUCATION AND PRACTICES FOR THE PROMOTION OF MENTAL HEALTH IN

\begin{abstract}
This text is a research report written as Conclusion Work of Latu Sensu Post-Graduation Course on Mental Health. Such research was developed following the qualitative approach and the case study method. This study aims to search and analyze the conceptions of psychology area professionals about mental health practices applied by health center teams of two campus of an Education, Science and Technology Federal Institute to teenagers enrolled on such. We explore the mental health conception built from the Psychiatric Reform and, as consequence, the building need of a community network of health attention and care. School can integrate such network, which could enable interesting action development possibilities promoting the mental health at teenage. The reason for choosing this case relies on the recent articulation experience with health and education - which is differentiated, introducing health centers inside schools, with multi-professional teams. Since this is a novel proposal, is important to find and understand how health professionals, workers on such Institute, realize it and how they comprise the school contribution possibilities related to action design with emphasis on the teenager's mental health. Research results show that such professionals' conceptions bring various novel possibilities, detailing with their reports, interesting practices already taken and implanted on their actuation campus.
\end{abstract}

Keywords: Mental Health. Education. Adolescence.

Recebido em: 22/2/2017

Aceito em: $17 / 8 / 2017$ 
Este trabalho surgiu em decorrência de uma pesquisa desenvolvida para o Trabalho de Conclusão do curso de Pós-Graduação Lato Sensu em Saúde Mental da Universidade Regional do Noroeste do Estado do Rio Grande do Sul (Unijuí). A pesquisa tem como objetivo principal compreender as principais ações já realizadas, com foco na promoção da saúde mental dos adolescentes matriculados nos cursos técnicos integrados ao Ensino Médio, desenvolvidas pelas equipes de saúde dos campi de um Instituto Federal de Educação, Ciência e Tecnologia, a partir da concepção dos psicólogos.

Para isso, realizou-se um estudo de caso relativo à concepção dos psicólogos dos campi, que contam com o centro de saúde e que se disponibilizaram a participar da pesquisa. Conforme Lüdke e André (2013), a pesquisa, do tipo estudo de caso, abarca um grande potencial, no sentido de que busca compreender uma determinada situação ou problema, com interesse central no entendimento daquilo que o caso tem de único e de singular. Sendo assim, para estas autoras “cada caso é tratado como tendo um valor intrínseco" (LÜDKE; ANDRÉ, 2013, p. 24), mesmo que, posteriormente, venham a perceber-se algumas semelhanças com outros casos ou situações.

Para o desenvolvimento desta pesquisa foram utilizados questionários (SHAUGHNESSY; ZECHMEISTER; ZECHMEISTER, 2012), buscando-se realizar um levantamento acerca de informações sobre o funcionamento geral do centro de saúde de cada campus, incluindo conhecer quais são os profissionais de saúde e há quanto tempo o campus conta com a atuação de cada um na equipe; verificar quais as principais práticas, já realizadas pelas equipes de saúde de cada campus, para promoção da saúde mental na adolescência; e identificar as concepções dos profissionais sobre as possibilidades de contribuições da escola no sentido da promoção da saúde mental dos adolescentes.

Vale ressaltar que o conceito de saúde mental aqui empregado é referente à concepção construída a partir da reforma psiquiátrica, em que a atenção à saúde deixa de se dar a partir de um modelo exclusivamente hospitalocêntrico, baseado somente no isolamento e na contenção do paciente, e de estar vinculada à ideia do mero controle do paciente, e passa a operar segundo um novo modelo de assistência à saúde mental, de forma aberta e de base comunitária, com um 
conceito ampliado de saúde, entendido agora como abrangendo uma maior complexidade a partir da integralidade, da qualidade de vida e do bem-estar do sujeito como um todo. Com isso, também, a ênfase deixa de ser somente a busca pela ausência de sintomas, e dá espaço às práticas de prevenção e de promoção em saúde mental.

A partir do movimento iniciado com a Reforma Psiquiátrica, tornou-se fundamental a construção de uma rede comunitária de cuidados à saúde, sendo esta muito maior do que o conjunto de serviços de saúde mental do município. Como destacado no documento Reforma Psiquiátrica e Política de Saúde Mental no Brasil (BRASIL, 2005, p. 25), "uma rede se conforma na medida em que são permanentemente articuladas outras instituições, associações, cooperativas e variados espaços das cidades”. É isto que define a rede de atenção à saúde mental como de base comunitária e o que se almeja é um movimento permanente de busca pela emancipação das pessoas com transtornos mentais. É somente a partir desta rede, e não de uma única instituição isolada, que se torna possível uma maior aproximação da atenção à saúde mental em toda a sua complexidade.

É nesse sentido que as escolas também encontram importantes possibilidades de integrar esta rede, e, assim, contribuir significativamente para a promoção da saúde mental de crianças e adolescentes. A promoção da saúde, com a Reforma Psiquiátrica, passa a realizar-se no próprio território ${ }^{3}$ dos sujeitos, em seus diversos espaços de convivência, incluindo, nestes, a escola.

\section{Sobre a Contextualização do Caso e a Conceitualização Teórica}

Inicialmente se faz necessária uma breve contextualização quanto à instituição em que se deu este estudo de caso, bem como de sua política de atenção à saúde dos discentes. Este estudo foi realizado em um Instituto Federal de Educação, Ciência e Tecnologia, que foi criado a partir da Lei 11.892, de

3 "O território é a designação não apenas de uma área geográfica, mas das pessoas, das instituições, das redes e dos cenários nos quais se dão a vida comunitária” (BRASIL, 2005, p. 26). 
29 de dezembro de 2008. São, portanto, institutos que surgiram recentemente, e que trazem consigo uma proposta inovadora no sentido da atenção integral à saúde no âmbito escolar; daí a importância de considerá-la na construção de pesquisas. Esta é uma proposta que já está contemplada até mesmo na missão destes institutos - promover a educação profissional, científica e tecnológica, pública, por meio de ensino, pesquisa e extensão, com foco na formação inte$\mathrm{gral}^{4}$ do cidadão.

Assim, atendendo a esta missão, foi regulamentada recentemente esta proposta inovadora de articulação entre saúde e educação com a aprovação da Política de Atenção à Saúde dos Discentes deste instituto federal, a partir da resolução de seu Conselho Superior (Consup ${ }^{5}$ ) no 014/2015, de 16 de março de 2015. Entre outros aspectos, a elaboração desta Política levou em consideração: a) o artigo 196 da Constituição Federal de 1988, em que se reconhece a saúde como "direito de todos e dever do Estado, garantido mediante políticas sociais e econômicas que visem à redução do risco de doença e de outros agravos e ao acesso universal e igualitário às ações e serviços para sua promoção, proteção e recuperação"; b) a Lei 8.080/90, em que se destaca novamente a saúde como direito fundamental do ser humano, sendo dever do Estado prover as condições necessárias para isso; e c) o Decreto 7.234/2010, que dispõe sobre o Programa Nacional de Assistência Estudantil (PNAES), que estabelece programas, projetos e ações em diferentes eixos de atuação, sendo um deles relativo à atenção à saúde, por considerar que a permanência do discente junto à Instituição está, também, relacionada a sua qualidade de vida.

Dessa forma, para a elaboração do documento que trata da Política de Atenção à Saúde dos discentes deste instituto federal aqui pesquisado, parte-se do conceito de saúde como um processo relacionado à qualidade de vida dos sujeitos e ao acesso aos demais direitos sociais, e não apenas como a simples ausência de doença. Como mencionado no próprio documento, esta é uma "política transversal, integrada e intersetorial, a qual faz dialogar as diversas áreas,

4 Grifo nosso.

5 O Conselho Superior (Consup) é o órgão máximo, de caráter consultivo e deliberativo, do Instituto Federal de Educação, Ciência e Tecnologia. 
setores e a sociedade, compondo redes de compromissos e corresponsabilidades quanto à qualidade de vida, em que todos sejam partícipes no cuidado com a saúde" (CONSELHO..., 2015, p. 20).

Cabe destacar que, apesar desta Política ter sido aprovada tão recentemente, cada campus já vem realizando ações em saúde e já conta com profissionais da área há mais tempo. Sendo assim, esta resolução não marca o início das ações em saúde, mas regulamenta seu funcionamento dentro de cada campus deste instituto. Nesse sentido, e também levando em consideração o caráter inovador desta proposta de trabalho, que envolve um trabalho conjunto entre Saúde e Educação, torna-se importante pesquisar como tem sido esta experiência, mesmo que ainda tão inicial, identificando, também, as ações que já vêm sendo realizadas, porém, neste caso, mais especificamente quanto à promoção de saúde mental na adolescência.

Ainda, conforme relatório da Organização Mundial da Saúde (2001), durante a adolescência é comum iniciar o aparecimento de sintomas relacionados a transtornos mentais, ao mesmo tempo em que a atenção conferida à saúde mental dos jovens é insuficiente. Este fato evidencia-se pela escassez de pesquisas envolvendo a saúde mental na adolescência, especialmente em interface com a educação.

De acordo com o Pacto Europeu para a Saúde Mental e o Bem-estar (2008), mais de 50\% das doenças mentais têm o seu início durante a adolescência, e a educação é destacada como uma das áreas prioritárias de ações voltadas à saúde mental dos jovens.

Apesar da maioria dos casos de problemas relacionados à saúde mental se iniciar na adolescência, Kieling (2012, p. 124) afirma que "ações são necessárias para reverter a escassez de pesquisas sobre a saúde mental de crianças e adolescentes". Até mesmo Freud, já em 1905, afirmava que na puberdade o sujeito vive um momento de novas combinações e composições, sendo este um período oportuno para a ocorrência de perturbações patológicas. Mesmo assim, ainda existem poucos estudos sobre a saúde mental de adolescentes, principalmente relacionados à educação. 
No Brasil, a partir da Lei de Diretrizes e Bases da Educação Nacional (1996), artigo $4^{\circ}$, a obrigatoriedade do Ensino Fundamental passa a ser garantida, sendo que a partir da Lei 12.796/2013, ${ }^{6}$ a Educação Básica passa a ser obrigatória a todos com idade entre 4 e 17 anos. Com isso, passa a haver a necessidade de permanência, por longos períodos de tempo, de crianças e adolescentes no âmbito escolar. A escola torna-se um espaço privilegiado para que problemas relacionados à saúde mental se manifestem precocemente, e, assim, também torna-se um espaço estratégico para a promoção da saúde mental de crianças e adolescentes.

Uma maior proximidade entre os setores de saúde e educação é apontada por Estanislau e Bressan (2014) como um importante fator no sentido da promoção de saúde mental dos adolescentes, levando em consideração que, a partir da Política Nacional de Humanização (2003), as práticas em saúde devem ser no sentido da construção e potencialização da autonomia dos sujeitos, da corresponsabilização e do protagonismo nas práticas coletivas de fazer saúde. Assim, conforme Gomes e Loureiro (2013, p. 33):

A promoção de saúde mental é, por isso, uma responsabilidade de toda a sociedade: no comércio e na indústria, no planejamento local, na educação, na cultura, na segurança nacional e em tantos outros aspetos da sociedade, promovendo a participação efetiva de todos os cidadãos.

De acordo com Estanislau e Bressan (2014, p. 16), "escolas são mais acessíveis à população jovem que os serviços de saúde mental e propiciam a realização de intervenções com menos estigma para alunos e familiares". Segundo estes autores, a literatura em saúde mental passa a identificar o sistema escolar como principal núcleo de promoção e prevenção de saúde mental para os jovens, "atuando no desenvolvimento de fatores de proteção e na redução de riscos ligados à saúde mental” (p. 16).

${ }^{6}$ Estabelece as diretrizes e bases da educação nacional para dispor sobre a formação dos profissionais da educação e dar outras providências. 
Dessa forma, é importante pesquisar como vem efetivando-se esta proposta inovadora dos centros de saúde nos Institutos Federais, bem como quais têm sido as principais ações já realizadas com adolescentes no sentido da promoção da saúde mental na escola.

Antes de mencionar os principais resultados da pesquisa, porém, se faz necessário esclarecer ainda qual a concepção de adolescência presente neste estudo. Compreende-se aqui a adolescência a partir do viés psicanalítico, que a aborda desde as operações simbólicas presentes neste tempo constitutivo.

A partir da psicanálise, considera-se que a operação psíquica do adolescer envolve uma reatualização e reedição dos mais diversos conteúdos inconscientes da infância, bem como de conflitos subjetivos até então mantidos suspensos e silenciados pela latência. Entre estas ressignificações, destaca-se a retomada de conteúdos infantis e a necessidade de atribuir-lhes novos sentidos, passando-se cada vez mais a tecer o próprio caminho, não mais ancorado na figura dos pais da infância, que até o momento ainda eram considerados os únicos ideais a serem seguidos, mas rumo a novas identificações e à construção de seu lugar próprio, agora no social.

O processo do adolescer ${ }^{7}$ caracteriza-se, assim, como um tempo transitório de passagem para uma nova posição - de assumir um lugar seu, no social e no mundo adulto; passagem esta que, de diversas formas, os jovens buscam tornar menos árdua, por meio, por exemplo, das identificações e da formação dos grupos adolescentes.

Conforme o entendimento de Ruffino (1993), o adolescer passou a fazer-se necessário, a partir da sociedade moderna, enquanto trabalho psíquico individual, que exige esforço no sentido de resolver para si mesmo diversos enigmas, como "O que o Outro quer e espera de mim?", "Quem eu sou?", “O que serei?", "O que fará de mim reconhecido como um adulto?", entre tantos

7 Termo que tem origem no verbo latim "adolescere", que significa crescer. Foi utilizado por Ruffino (1993) para remeter ao processo psíquico que acontece em substituição aos antigos ritos de passagem estipulados pelas sociedades, perdidos com a modernidade, que organizavam simbolicamente e cumpriam com esta importante função de marcar a passagem da vida infantil para a adulta. 
outros, mas que exigem sempre um grande esforço, muitas vezes vivido na forma de "crises e tensões" advindas da necessidade que se impõe durante este tempo de construção de um nome próprio - o que exigirá a retomada e reelaboração de conflitos infantis, bem como a tarefa de "desenvolver e orientar, em diferentes sentidos (sem abandonar), aquilo que ficou do tom afetivo das relações constituídas na infância" (GURFINKEL; PENNACCHI, 1993, p. 106), transformando-as em uma criação sua.

Afinal, não é por acaso que se manifestam tão frequente e fortemente, junto com todos estes enigmas, várias complicações durante a adolescência, tais como a delinquência, a toxicomania, as depressões, as rebeldias e transgressões, as marcas e sintomas corporais (por exemplo, as bulimias e anorexias) - cada vez mais frequentes entre os adolescentes hoje. Em muito, estas complicações se devem, justamente, ao intenso trabalho psíquico próprio a este conflituoso tempo da constituição psíquica, que é a adolescência, que, com a modernidade, passou a exigir maior esforço por parte destes sujeitos, tornando-se mais difícil e problemático, uma vez que os dispositivos simbólicos sociais organizadores desta passagem para a vida adulta, nas sociedades tradicionais, perderam sua eficácia com a modernidade.

A adolescência, para a psicanálise, passou, então, a ser um tempo não atrelado à faixa etária, mas, sim, a um não lugar, que leva a diversos movimentos, e estes conduzem a um intenso trabalho de reorganização psíquica, que, por si só, já contém elementos suficientes para abrir espaço a novas irrupções de formações psicopatológicas na adolescência. Rassial (1999), em Loucura e adolescência, também menciona que é frequente a entrada na psicose, por exemplo, no registro de uma crise adolescente.

Como ele mesmo afirma, "as questões do adolescente sobre seu corpo, sua identidade, sua integração no mundo e na sociedade, seu papel sexual, identificam-se com as questões levantadas pelas psicoses" (p. 126). Por isso, então, tão importante é que se proporcione práticas de promoção de saúde mental neste tempo constitutivo, sendo a escola um espaço privilegiado para isso. 


\section{Algumas Considerações sobre os Caminhos Metodológicos}

Esta pesquisa foi realizada a partir de uma abordagem qualitativa, levando-se em consideração que, nesta, busca-se a obtenção de dados descritivos, bem como uma maior compreensão do problema pesquisado a partir das perspectivas dos participantes, ou seja, dos significados atribuídos por eles às questões focalizadas; não há uma preocupação quanto a mensurar, enumerar e/ou quantificar situações ou eventos. Nesta perspectiva, Lüdke e André (2013) afirmam que o estudo de caso está entre as várias formas que uma pesquisa qualitativa pode assumir, com grande potencial para estudar questões relacionadas às escolas.

Como uma das características importantes da pesquisa qualitativa, estas mesmas autoras enfatizam a necessidade de o pesquisador manter-se atento aos significados e interpretações atribuídos pelos sujeitos, às situações e aos problemas apresentados. Isso porque nos estudos qualitativos há espaço para a busca por entender a perspectiva dos participantes, bem como suas maneiras de compreensão das questões abordadas.

Como afirmam estas autoras, "ao considerar os diferentes pontos de vista dos participantes, os estudos qualitativos permitem iluminar o dinamismo interno das situações, geralmente inacessíveis ao observador externo (LÜDKE; ANDRÉ, 2013, p. 14). Assim, para compreender o problema que está sendo estudado os horizontes dos sujeitos e suas interpretações são de fundamental importância, uma vez que permitem a construção de aspectos não inicialmente pensados ou imaginados.

O estudo de caso, conforme Lüdke e André (2013), é sempre bem delimitado; constitui-se em uma unidade, dentro de um sistema mais amplo, que direciona o interesse ao que o caso tem de único e singular, focaliza a realidade de forma contextualizada e está sempre atento e aberto a novos elementos que possam surgir no decorrer da pesquisa, objetivando-se uma maior compreensão quanto à situação estudada. 
Outro importante autor que trabalha com estudo de caso e que, atualmente, é referência neste tema, é Robert Yin (2015). Ele o apresenta como uma das várias maneiras de realizar uma pesquisa em ciências sociais. Para Yin (2015), esta é uma metodologia de grande relevância para contribuir com o conhecimento de fenômenos individuais, grupais, organizacionais, sociais, políticos, entre outros, sendo apropriada para conhecê-los, uma vez que possibilita ao pesquisador focar em um caso específico e buscar uma perspectiva holística quanto a este. Assim, alguns dos principais motivos de escolha do estudo de caso para a realização desta pesquisa se referem ao seu potencial para a compreensão dos fenômenos nas pesquisas em educação, descrito tanto por Yin (2015) quanto por Lüdke e André (2013).

Também, a fim de buscar uma compreensão mais ampla quanto ao problema central desta pesquisa - "Quais são as principais práticas de promoção em saúde mental do adolescente, que vêm sendo desenvolvidas nos campi deste Instituto Federal de Educação, Ciência e Tecnologia, cujos centros de saúde já estão em funcionamento, a partir da concepção do profissional da área da psicologia ?" $^{\text {", }}$, utilizou-se como método de levantamento de dados a aplicação de um questionário descritivo, sem alternativas previamente fixadas, a partir do qual se buscou o livre relato dos psicólogos, de acordo com suas concepções e interpretações dos questionamentos apresentados.

Optou-se pelo questionário via e-mail, em razão da grande distância em relação aos campi que se propuseram a participar da pesquisa, e do longo tempo que se levaria para realizá-la caso tivesse de haver o deslocamento até os mesmos. Conforme Shaughnessy, Zechmeister e Zechmeister (2012), os questionários são um dos instrumentos mais utilizados em levantamento de dados e proporcionam um meio eficiente para descrever os pensamentos e as concepções das pessoas. Para estes mesmos autores, os levantamentos realizados pela internet compõem uma "ferramenta indispensável para os psicólogos que fazem pesquisa, especialmente pela comunicação via correio eletrônico (e-mail)" (p. 422). Para

${ }^{8}$ Cabe ressaltar que neste estudo se optou por pesquisar o referido problema, a partir da concepção dos psicólogos, em razão de que nesta instituição é, principalmente, a este profissional que as demandas relativas à saúde mental são, mais frequentemente, endereçadas. 
eles, a internet é um instrumento interessante e vantajoso para pesquisas pela sua eficiência, baixo custo, pelo tempo reduzido em relação a outros tipos de levantamentos e, também, pela possibilidade de os participantes responderem quando lhes for possível.

Apesar destas vantagens, no entanto, se está ciente também de alguns riscos na utilização de questionários via internet, como, por exemplo, a maior objetividade dos dados, não sendo possível observar o ambiente e outros fatores relevantes que uma entrevista, diretamente com os sujeitos envolvidos, proporcionaria. Além disso, sabe-se das possibilidades de surgirem problemas referentes à pouca participação e disponibilidade em responder ao questionário.

Quanto, porém, ao primeiro risco mencionado, nesta pesquisa objetiva-se compreender as ações de promoção em saúde mental nos centros de saúde a partir da concepção dos psicólogos, não sendo tão prejudicial, portanto, o fato de não se tornar possível observar como efetivamente se dá este funcionamento, uma vez que a ênfase está na concepção dos profissionais. Quanto ao segundo risco, também não é essencial, neste estudo, uma grande quantidade de participações, mas pelo menos a contribuição de dois campi, para que se possa realizar um comparativo entre os mesmos.

\section{Discussões e Resultados}

Esta pesquisa foi realizada com três profissionais da área da psicologia que se prontificaram a responder ao questionário. Dois destes psicólogos atuam em um mesmo campus (campus A), que é um dos mais antigos desta instituição, e que, portanto, conta com o setor de saúde em pleno desenvolvimento de suas atividades a um tempo maior em relação aos outros campi, servindo, assim, como bons representantes desta prática tão inovadora, que proporciona uma nova forma de articulação entre ações de saúde mental e educação. O campus B, apesar de ser um pouco mais recente, também já está com as atividades do centro de saúde em efetivo andamento. 
A fim de relatar os principais dados identificados durante a pesquisa, bem como os resultados alcançados, será realizado, agora, o comparativo entre os dois campi (A e B) a partir de cada questão apresentada e respondida pelos profissionais.

Quanto à primeira questão, que se refere à composição das equipes dos centros de saúde dos campi e ao tempo de atuação de cada profissional, percebeu-se similaridade no que se refere aos profissionais que compõem ambas as equipes, sendo estas compostas por psicólogos, nutricionistas, médicos, técnicos de enfermagem e odontólogos. As únicas variações, neste sentido, se referem ao fato de que o campus A possui também um auxiliar de saúde bucal, à diferença do campus $\mathrm{B}$, e um odontólogo e um técnico de enfermagem a mais, o que se deve ao fato de ser mais antigo e atender a um público maior de estudantes. É possível melhor observar estes dados na Tabela a seguir.

Tabela 1 - Profissionais integrantes das equipes de saúde nos campi A e B

\begin{tabular}{|l|l|}
\hline CAMPUS A & CAMPUS B \\
\hline 2 Psicólogos & 2 Psicólogos \\
\hline 1 Nutricionista & 1 Nutricionista \\
\hline 1 Médico & 1 Médico \\
\hline 2 Técnicos de Enfermagem & 1 Técnico de Enfermagem \\
\hline 2 Odontólogos & 1 Odontólogo \\
\hline Auxiliar de Saúde Bucal & \\
\hline Fonte: Questionários respondidos pelos psicólogos participantes desta pesquisa.
\end{tabular}

Sobre o tempo de atuação no setor, os profissionais que há mais tempo estão em ambas as instituições são os psicólogos, técnicos de enfermagem e nutricionistas; no campus A os profissionais mais antigos têm em torno de 11 anos, enquanto no campus B têm, aproximadamente, 7 anos de instituição.

Estes dados são interessantes para possibilitar um olhar quanto às diferenças entre os campi e, também, quanto à forma como as equipes estão organizadas. Percebe-se, com isso, que o campus A, sendo maior e mais antigo, encontra também melhores possibilidades de já estar com o setor de saúde bem-estruturado e com muitas ações já desenvolvidas quanto à saúde mental. 
No que diz respeito à questão que se refere à dinâmica de funcionamento dos centros de saúde, os psicólogos do campus A destacaram que este setor está organizado da seguinte forma: realiza atendimentos a alunos, servidores terceirizados e estagiários e estes se dão de forma ininterrupta, das $8 \mathrm{~h}$ às 23 horas; os atendimentos médicos, de enfermagem e psicológicos acontecem por livre-demanda, enquanto os atendimentos odontológicos exigem agendamento prévio e planejamento por turmas; os profissionais da área da psicologia também atendem conforme encaminhamentos, e realizam acompanhamento dos alunos durante os conselhos de classe, entrega de pareceres, devolutiva para os pais. De forma geral, a equipe de saúde organiza um calendário anual para a participação de seus profissionais em projetos de prevenção e promoção da saúde.

Em relação a este aspecto, no campus B os atendimentos são, preferencialmente, destinados aos alunos, mesmo que, eventualmente, possam ser realizados também com servidores. O setor procura manter-se aberto durante os três turnos de funcionamento da instituição. Os atendimentos de todos os profissionais acontecem mediante livre-demanda, conforme as necessidades, e as atividades gerais, como atendimento inicial ao público e recebimento de atestados, são realizadas por todos os integrantes do setor.

Estes aspectos podem ser melhor visualizados a partir da Tabela 2. 
Tabela 2 - Dinâmica de funcionamento do centro de saúde nos campi A e B

\section{CAMPUS A}

Atendimentos a alunos, servidores terceirizados e estagiários;

Atendimentos ininterruptos, das $8 \mathrm{~h}$ às 23 horas;

Atendimentos médicos, de enfermagem e psicológicos acontecem por livre-demanda, enquanto os atendimentos odontológicos exigem agendamento prévio e planejamento por turmas;

Psicólogos atendem conforme encaminhamentos. Realizam acompanhamento dos alunos durante os conselhos de classe, entrega de pareceres, devolutiva para os pais;

Equipe de saúde organiza um calendário anual para a participação de seus profissionais em projetos de prevenção e promoção da saúde.

\section{CAMPUS B}

Atendimentos preferencialmente destinados aos alunos, mesmo que, eventualmente, possam ser realizados também com servidores;

$\mathrm{O}$ setor procura manter-se aberto durante os três turnos de funcionamento da Instituição;

Atendimentos mediante livre-demanda, conforme as necessidades;

Atividades gerais, como atendimento inicial ao público e recebimento de atestados, são realizadas por todos os integrantes do setor.

Fonte: Questionários respondidos pelos psicólogos participantes desta pesquisa.

Perpassa aqui, em ambos os campi, a concepção dos profissionais quanto à necessidade de acesso universal e igualitário aos serviços de saúde, e, principalmente, no campus $\mathrm{B}$, há a ideia da existência de um trabalho conjunto entre seus diversos profissionais; aspecto este que demonstra a realização da atenção à saúde não mais centralizada em um único profissional, como, por muito tempo, esteve focalizada apenas na figura do médico, porém evidencia-se uma maior fundamentação na cooperação e corresponsabilização dos profissionais.

Quanto ao terceiro item pesquisado, que diz respeito às principais práticas já desenvolvidas no sentido da promoção da saúde mental, os psicólogos do campus A mencionaram uma grande diversidade de atividades, demonstrando uma concepção ampliada de saúde mental. Apesar de não ser mencionada a Reforma Psiquiátrica, a compreensão construída a partir deste movimento esteve sempre presente e permeando as descrições das ações já realizadas com vistas à promoção da saúde mental no âmbito desta escola. 
Serão citados aqui apenas alguns exemplos, como: construção e execução de projetos multidisciplinares, envolvendo temas como sexualidade, drogadição, cidadania e projeto de vida; ${ }^{9}$ realização de atendimentos individualizados, conforme a necessidade; desenvolvimento de atividades em sala de aula sobre temas em evidência na turma, como relacionamento, bullying, drogas e outros; acolhida, escuta e orientações a alunos, pais e servidores; promoção e fomento de atividades culturais e desportivas; encaminhamento para outros profissionais da saúde, quando necessário, "estabelecendo e fortalecendo a rede de atenção com o município"; participação das reuniões familiares; "atuação em conjunto com os demais setores da escola"; entre tantas outras ações mencionadas.

Nestas escritas destaca-se a concepção e a compreensão da necessidade de fortalecimento da rede comunitária, o que remete ao fato de o centro de saúde não estar isolado em suas práticas dentro da escola, mas de ele vir realizando o que foi anteriormente citado e previsto na Política de Atenção à Saúde dos Discentes do Instituto Federal, quando esta se diz intersetorial, envolvendo, como mencionado nas falas anteriores, um trabalho conjunto com os outros setores da escola, com as diversas áreas, mas, também, não permanecendo centralizado apenas na instituição de ensino, e, sim, mantendo um diálogo com os demais espaços que constituem o território dos sujeitos com a sociedade, "compondo redes de compromisso e corresponsabilidades quanto à qualidade de vida, em que todos sejam partícipes no cuidado com a saúde" (CONSELHO..., 2015, p. 20).

No campus B foram destacadas, principalmente, ações voltadas à avaliação de saúde dos alunos (oftalmológica, de glicemia, avaliação de peso, saúde bucal, etc.), demonstrando uma concepção de indissociabilidade da saúde física e mental; foram mencionadas práticas relacionadas à abordagem de temáticas, como sexualidade, consumo de álcool e outras drogas. ${ }^{10}$

Aqui, mais uma vez, transparece a concepção de saúde atrelada ao entendimento quanto à integralidade do sujeito, e não mais à fragmentação deste e de sua saúde, como se houvesse a possibilidade de dissociá-la em partes, em

9 Exemplos de alguns projetos desenvolvidos: Projeto "Escolhas", de orientação vocacional, direcionado para os alunos concluintes do Ensino Médio; Projeto Bullying - "Faça amigos, não faça bullying"; Projeto "Dicas de Estudo".

${ }^{10}$ Este psicólogo apresentou respostas mais sucintas quanto a esta questão. 
que cada profissional se responsabilizaria pelo cuidado de somente um de seus fragmentos. Ao contrário disso, os profissionais participantes desta pesquisa demonstraram a compreensão da importância do trabalho conjunto entre os diversos profissionais da saúde, assim como também da necessidade de proporcionar uma grande variedade de ações quando se objetiva a promoção da saúde mental. Isto, porque práticas culturais, esportivas, de lazer e relativas a ações sociais, são tão importantes quanto os atendimentos individuais de cada área, quando o conceito de saúde que se tem presente diz respeito à integralidade dos sujeitos e da sua saúde.

Para melhor comparativo entre os dois campi quanto às respostas a esta questão, apresentamos a seguinte Tabela.

Tabela 3 - Principais práticas já desenvolvidas com o objetivo de promoção da saúde mental na adolescência, nos campi A e B

\section{CAMPUS A}

Construção e execução de projetos multidisciplinares, envolvendo temas como sexualidade, drogadição, cidadania e projeto de vida;

\section{CAMPUS B}

Ações voltadas à avaliação de saúde dos alunos (oftalmológica, de glicemia, avaliação de peso, saúde bucal, etc.);

Realização de atendimentos individualizados, conforme a necessidade;

Desenvolvimento de atividades em sala de aula, sobre temas em evidência na turma, como relacionamento, bullying, drogas e outros;

Acolhida, escuta e orientações a alunos, pais e servidores;

Promoção e fomento de atividades culturais e desportivas;

Encaminhamento para outros profissionais da saúde, quando necessário, estabelecendo e fortalecendo a rede de atenção com o município;

Participação das reuniões familiares;

Atuação em conjunto com os demais setores da escola.
Práticas relacionadas à abordagem de diversas temáticas, conforme necessidade. Exemplo: sexualidade, e, consumo de álcool e outras drogas.

Fonte: Questionários respondidos pelos psicólogos participantes desta pesquisa. 
No que diz respeito ao último questionamento - a concepção dos profissionais da psicologia acerca das possibilidades de contribuição das escolas no sentido da promoção da saúde mental na adolescência -, os três profissionais afirmaram que muitas são as oportunidades de ações e de práticas neste sentido.

O profissional 1, do campus $\mathrm{A}$, mencionou que "as instituições de ensino, principalmente as escolas de turno integral, possibilitam um trabalho contínuo e integrado (...), com ações que promovam a saúde mental". Percebe-se, nesta concepção, o pensamento de que o maior tempo de permanência dos adolescentes nas escolas, organizadas em turno integral, possibilita uma maior continuidade das ações em saúde mental, e também a organização de práticas conjuntas, interdisciplinares e de forma integrada. Este entendimento está de acordo com o que Estanislau e Bressan (2014) destacam em Saúde Mental na Escola, acerca do grande potencial desta quanto à promoção da saúde mental dos adolescentes, posto que a escola se encontra mais próxima a eles do que os serviços específicos de saúde mental, bem como apresenta maiores possibilidades de desenvolver práticas voltadas a ela, de forma menos estigmatizada, tanto a pais quanto também aos jovens estudantes.

A psicóloga 2, do campus A, relacionou, nesta resposta, a saúde mental mais a aspectos psicológicos, apesar de nas questões anteriores ter demonstrado claramente um entendimento mais ampliado quanto à saúde, incluindo nela aspectos físicos, psíquicos e sociais. Esta profissional, porém, também apostou em políticas voltadas à saúde mental nas escolas, na busca por "fomentar reflexões e novos fazeres relativos à prevenção e promoção" desta em relação ao adolescente.

O psicólogo 3, do campus B, afirmou que "certamente a escola oferece inúmeras possibilidades no âmbito da promoção de saúde mental", e que esta deveria ter a saúde como tema transversal e multidisciplinar, proporcionando ações de prevenção, promoção e atenção à saúde física e mental dos estudantes. Para ele, "é consenso que as condições necessárias para que sujeitos e comunidades sejam mais saudáveis não dependem unicamente de o indivíduo ter 
acesso ao tratamento psicológico", o que demonstra seu entendimento da saúde influenciada por múltiplos fatores, e não meramente como bem-estar físico ou psíquico de forma fragmentada.

Enfim, ao discorrer sobre as respostas fornecidas diante das questões apresentadas, percebe-se o quanto as concepções dos psicólogos destas duas instituições de ensino encontram-se permeadas não mais pelo paradigma de saúde médico-biológico, hospitalocêntrico quanto à abordagem relativa à saúde mental, nem sequer estão apoiadas, exclusivamente, em aspectos psíquicos. Transparece, porém, um paradigma em que há a compreensão da integralidade da saúde, partindo-se de uma concepção unitária do ser humano, e buscando-se a consolidação de uma rede de serviços de atenção à saúde mental, favorecendo a promoção desta no próprio contexto e comunidade de cada sujeito. Ou seja, por mais que os psicólogos não tenham explicitamente mencionado as contribuições do movimento da Reforma Psiquiátrica para o âmbito da saúde mental, estas contribuições apareceram transpassadas em suas formas de entendimento, bem como nas concepções destes quanto às práticas de saúde mental voltadas aos adolescentes nas escolas.

\section{Considerações (Não) Finais}

A partir deste estudo de caso, relativo às concepções dos profissionais da área da psicologia quanto às práticas de saúde mental desenvolvidas nesta instituição de ensino, que apresenta uma proposta inovadora de articulação entre os campos da saúde e da educação, à medida que contém um centro de saúde dentro da escola, vários aspectos puderam ser considerados:

- Apesar de o centro de saúde estar situado dentro do âmbito escolar, não parece haver um fechamento deste em si mesmo, mas sim um entendimento da necessidade da construção de uma rede comunitária de cuidados, constituída de diversos profissionais, setores, instituições, associações, agentes sociais e variados espaços da cidade. A escola, sendo uma das integrantes desta rede, que recebe grande número de adolescentes por longos períodos de tempo, 
corresponde a um dos importantes espaços do território destes sujeitos, com significativa oportunidade de desenvolver ações visando à promoção da saúde mental.

- A permanência destes adolescentes na escola, durante períodos prolongados, demonstra uma maior facilidade de realização, pela equipe de saúde, de um acompanhamento mais próximo e constante deles. $\mathrm{O}$ fato de a equipe estar situada neste âmbito demonstra facilitar a identificação, o planejamento e a organização de ações voltadas à promoção da saúde mental, de acordo com as diversas necessidades e demandas dos estudantes. Esta forma de organização do centro de saúde, dentro da instituição de ensino, parece permitir a identificação de certos problemas precocemente, bem como a realização da abordagem dos mesmos com os adolescentes, de forma a trabalhá-los de modo transversal, sem que o mesmo precise dirigir-se a um serviço específico de saúde mental, fato este que, por muitas vezes, é evitado pelo público adolescente em razão do grande estigma que esta procura, para eles, ainda representaria. Pode, assim, ser esta articulação de um centro de saúde, inserido dentro da escola, uma interessante possibilidade de proporcionar aos adolescentes algumas ações direcionadas à promoção de sua saúde mental em um tempo constitutivo quando tanto necessitam.

Além disso, o modelo de atuação da equipe, a partir da concepção dos profissionais, não parece seguir aquele centrado em uma única categoria profissional. Parece ter, todavia, a interdisciplinaridade como referência de intervenção, a qual produz uma rede de atendimento com ênfase no cuidado integral à saúde e na comunicação, não apenas entre os diversos profissionais, mas também entre os diferentes serviços públicos existentes no território, ampliando o cuidado em saúde mental e promovendo um olhar contextualizado e articulado entre os distintos espaços de cuidado.

Estes aspectos mencionados são, também, imprescindíveis para a consolidação da Reforma Psiquiátrica, que compreende a um

processo político e social complexo, composto de atores, instituições e forças de diferentes origens, e que incide em territórios diversos (...). Compreendida como um conjunto de transformações de práticas, saberes, valores culturais 
e sociais, é no cotidiano da vida das instituições, dos serviços e das relações interpessoais que o processo da Reforma Psiquiátrica avança, marcado por impasses, tensões, conflitos e desafios (BRASIL, 2005, p. 6).

Talvez um destes grandes desafios, que poderiam contribuir muito com a Reforma Psiquiátrica, configure-se por esta maior articulação e proximidade entre os setores da saúde e da educação na busca por maiores possibilidades de promoção da saúde mental dos adolescentes.

Assim, neste estudo, sem a pretensão de esgotar todas as discussões e reflexões cabíveis, espera-se somente a possibilidade de contribuir um pouco mais com o surgimento de novos questionamentos quanto ao campo desta temática apresentada, bem como a instigar novas pesquisas relativas à educação, saúde mental e adolescência.

\section{Referências}

BRASIL. Lei $n^{\circ}$ 9.394/96. Lei de Diretrizes e Bases da Educação Nacional. Brasília, 1996. In: <http://portal.mec.gov.br/arquivos/pdf/ldb.pdf>. Acesso em: 4 out. 2015.

Lei 12.796/2013. Altera a Lei $\mathrm{n}^{\circ}$ 9.394, de 20 de dezembro de 1996, que estabelece as diretrizes e bases da educação nacional, para dispor sobre a formação dos profissionais da educação e dar outras providências. Brasília, 2013. In: <http://www. planalto.gov.br/ccivil_03/_ato2011-2014/2013/lei/112796.htm>. Acesso em: 4 out. 2015.

BRASIL. Reforma psiquiátrica e política de saúde mental no Brasil. Brasília: Ministério da Saúde, 2005. In: <http://bvsms.saude.gov.br/bvs/publicacoes/Relatorio15_anos_Caracas.pdf>. Acesso em: 4 out. 2015.

BRASIL. HumanizaSUS: Política Nacional de Humanização. Brasília: Ministério da Saúde, 2003. In: <http://bvsms.saude.gov.br/bvs/publicacoes/humanizaSus.pdf >. Acesso em: 4 out. 2015.

CONSELHO SUPERIOR. Consup. Resolução $n^{\circ}$ 014/2015. Santa Maria: Consup, 2015. In: <http://www.iffarroupilha.edu.br/site/midias/arquivos/2015225163815767po litica_saude_discentes.pdf >. Acesso em: 4 out. 2015.

ESTANISLAU, G.; BRESSAN, R. (Org.). Saúde mental na escola. Porto Alegre: Artmed, 2014. 
FREUD, S. Três ensaios sobre a teoria da sexualidade. Edição Standard Brasileira das Obras Psicológicas Completas de Sigmund Freud. Rio de Janeiro: Imago Editora, 1905. Vol. VII.

GOMES, J. C. R.; LOUREIRO, M. I. G. O lugar da investigação participada de base comunitária na promoção da saúde mental. Revista Portuguesa de Saúde Pública, España: Elsevier, v. 31, n. 1, p. 32-48, 2013.

GURFINKEL, A. E. C.; PENNACCHI, R. F. S. Sobre o lugar da adolescência na teoria do sujeito. In: Adolescência: abordagem psicanalítica. São Paulo: EPU, 1993.

GUTIERRA, B. Adolescência, psicanálise e educação: o mestre "possível" de adolescentes. São Paulo: Avercamp, 2003.

KIELING, C. Saúde mental de crianças e adolescentes: uma perspectiva global. Porto Alegre, 2012. In: <http://www.lume.ufrgs.br/handle/10183/48970> Acesso em: 4 out. 2015.

LÜDKE, M.; ANDRÉ, M. Pesquisa em educação: abordagens qualitativas. Rio de Janeiro: EPU, 2013.

ORGANIZAÇÃO MUNDIAL DA SAÚDE (OMS). Relatório sobre a Saúde no Mundo - saúde mental: nova concepção, nova esperança. 2001. In: <http://www.abebe.org.br/ wp-content/uploads/oms2001.pdf>. Acesso em: 4 out. 2015.

. Pacto europeu para a saúde mental e o bem-estar. Organização Mundial da Saúde: 2008. In: <http://ec.europa.eu/health/mental_health/docs/mhpact_pt.pdf>. Acesso em: 4 out. 2015 .

RASSIAL, J. J. Loucura e adolescência. In: $O$ adolescente e o psicanalista. Rio de Janeiro: Companhia de Freud, 1999.

RUFFINO, R. Sobre o lugar da adolescência na teoria do sujeito. In: Adolescência: abordagem psicanalítica. São Paulo: EPU, 1993.

SILVA, M. C. P. A paixão de formar: da psicanálise à educação. Porto Alegre: Artes Médicas, 1994.

SHAUGHNESSY, J. J.; ZECHMEISTER, B. E.; ZECHMEISTER, S. J. Metodologia de pesquisa em psicologia. 9. ed. Porto Alegre: AMGH, 2012.

YIN, R. K. Estudo de caso: planejamento e métodos. 5. ed. Porto Alegre: Bookman, 2015. 